\title{
Job Satisfaction: Analysis of the Institute of Public Administration
}

\author{
Fahad alrefaei* \\ Instructor at Institute of public administration \\ Kingdom of Saudi Arabia
}

\begin{abstract}
*Corresponding Author: Fahad alrefaei, Instructor at Institute of public administration, Kingdom of Saudi Arabia
\end{abstract}

\begin{abstract}
Job satisfaction is an important topic that is receiving increasing global attention, this is because the employees' satisfaction in an organization and the work environment is reflected in their efficiency and performance, and thus the success of the organization. This article focuses on the lessons that can be extracted from the Institute of Public Administration's success in attaining high ranks in the standards of job satisfaction in Saudi Arabia".
\end{abstract}

Keywords: Institute of Public Administration, Job satisfaction, public sector.

\section{INTRODUCTION}

Job satisfaction is a measure of how happy employees are with their jobs and the environment around them. There are certainly several factors affecting an employee's happiness. Job satisfaction differs from one employee to another; some employees may view a high salary as something that provides job satisfaction, some may see that job satisfaction is achieved through the availability of training and education opportunities, and some may focus on the psychological aspect of the job. Spector, in his book "Job Satisfaction: Application, Assessment, Causes, and Consequences" published in (1997), defined job satisfaction as all the feelings that a given individual has about their job and its various aspects. Furthermore, Moyes et al (2008) agreed with Spector that job satisfaction may be described as how pleased an employee is with his or her position of employment, environment, etc. The purpose of this article is to achieve the following:

1) Discuss job satisfaction and the factors that influence it,

2) Analyze the Institute of Public Administration and how it achieved high levels of job satisfaction.

\subsection{Definition of Job Satisfaction}

Despite the interest of psychologists and researchers in this topic, they have different definitions for job satisfaction. They could not settle on a single definition for it because it is a flexible and broad concept that cannot be reduced to one definition. If you look closely, you will find that the concept of satisfaction, in general, depends on how good you feel about something, and the extent of happiness and pleasure you feel when achieving or obtaining it. One definition of job satisfaction is "any combination of psychological, physiological, and environmental circumstances that cause a person to truthfully say I am satisfied with my job" (Hoppock; 1935). Moreover, Job satisfaction is defined by Locke (1976) as "a pleasurable or positive emotional state resulting from the appraisal of one's job and job experiences". In 2006, Armstrong published a book called "A Handbook of Human Resource Management Practice", where he defined job satisfaction as "the attitudes and feelings that people have about their jobs". In the year 2004, Statt defined job satisfaction as " the extent to which a worker is content with the rewards they get out of their job, particularly in terms of intrinsic motivation".

To conclude, regardless of their different perspectives on job satisfaction, the psychologists and researchers agree on the definitions of job satisfaction being about personal emotions. If the employees have positive feelings at work, their attitudes toward the job will be defined as job satisfaction. Otherwise, they will be considered unsatisfied. 


\section{Factors Affecting Job Satisfaction}

Although job satisfaction is related to several psychological and environmental factors that are difficult to list, there are several main factors that have an important role in influencing job satisfaction. This includes:

\section{$>$ Career Development}

There is no doubt that the opportunities for promotion and career development are important in the life of every employee and represent an important achievement in their lives. Factors such as promotion opportunities, training and education programs, opportunities to use skills and abilities, and equal opportunities for the different genders are important factors in achieving job satisfaction. Studies have shown that there is a direct relationship between these factors and job satisfaction. According to Society for Human Resource Management (2016)more than half of the employees (55\%) rated opportunities to use their skills and abilities at work as a very important contributor to their job satisfaction. Moreover, $27 \%$ of employees who participated mentioned that they are looking for a job outside the organization because they are looking for better development opportunities. This demonstrates that career development is crucial to maintaining the work-force within the organization.

\section{$>$ Compensation and Benefits}

Wages and salaries are of great importance as they have an economic power that motivates employees to fulfill their various desires and needs in the organization, in addition to being an indication of the social position of the individual in society. The definition of wages, to put it simply, is an amount of money that is paid to employees for their effort and skills at work. Looking at SHRM's report (2016), it seems that the importance employees place on salaries as a factor contributing to job satisfaction continues to increase. The report shows that benefits are ranked the third most important factor with 60 percent rating them as important to job satisfaction. Despite the importance of financial compensation, the Bamboo HR report issued in (2016) states that "Nearly 30\% of employees would rather be recognized for their work accomplishments in a company-wide email from a company executive than receive a monetary bonus of $\$ 500$ that isn't openly publicized by a superior to their coworkers"

\section{$>$ Working Environment}

The work environment affects the degree of employee satisfaction. Variables of the work environment such as lighting, temperature, noise, cleanliness, and work methods have occupied the interest of researchers, and their studies have been focused on the impact of these physical factors on the productive performance of individuals. Hashim et al (2011) made it clear that "the office environment would influence the actions of employees and could affect their work".

\section{$>$ Respect and Appreciation}

Respect and appreciation are key requirements for a healthy work environment that promotes teamwork and increases productivity in the workplace. It also lets employees know that they are valued for their capabilities and achievements and that their role is important to the success of the organization. Feeling respected and appreciated fosters a positive work culture where employees are loyal and passionate about doing their best for the organization. In a survey conducted on 500 employees and published in the book "What People Want" by Terry Baconin (2006), 86\% of employees rank trust as one of their top needs. Moreover, another survey conducted in (2006) by the Society for Human Resource Management shows that $67 \%$ of employees deemed respect to be very important for their satisfaction with the job. $71 \%$ of employees were satisfied with the level of respect they were given at their organization. These results demonstrate the importance of the psychological aspect and the surrounding environment in influencing job satisfaction.

\subsection{The Institute of Public Administration}

The Institute of Public Administration, established in 1961, is headquartered in Riyadh, Kingdom of Saudi Arabia, and has six branches in different cities in Saudi Arabia. The institute was established with the purpose of raising the efficiency of public sector employees. It also provides several diploma programs for high school graduates and bachelor's graduates. Moreover, the institute offers several training programs and management consulting for the public and private sectors. According to the latest statistics issued by the institute regarding human resources, the number of employees of the 
institute is exceeding 2000 employees, and the majority of them are working in the headquarters. The institute seeks to recruit the best competencies and it pays great attention to human resources and always strives to reduce obstacles and provide amenities for its employees to complete their work (Achievement report, 2019). This led the institute to win the award for the best work environment for 2019(Great place to work, 2019). It also obtained high results in the percentage of employee satisfaction with the work environment (61\%) based on a report by the Ministry of Human Resources and Social Development (Satisfaction report, 2020). There is no doubt that many factors led to the institute obtaining these great results and achieving this success. These factors include:

\section{Training and Scholarship Programs}

Scholarships and training programs are among the benefits provided by the Institute of Public Administration. This contributed to fulfilling job satisfaction for employees. In 2019, 933 employees participated in training programs, which makes up about $50 \%$ of the total number of employees. These training programs contribute to the development of the employees' skills. Moreover, scholarship programs are considered of the most important programs offered by the Institute for employee development. Currently, 189 employees are studying in the US, UK, and Australia. These programs help achieve the institute's vision of being a leading partner in the field of administrative development.

\section{$>$ Encouraging Innovation}

Due to the importance of innovation and encouraging employees to find solutions to the problems they face in their workplace, the Institute of Public Administration launched a platform called "Innovation". This platform aims to indulge employees in suggesting solutions to problems facing the institute. The winner then gets valuable prizes. It also contributes to increasing connection and engagement between employees and senior management, which contributes to increased job satisfaction(Achievement report, 2019). According to a survey conducted by the Society for Human Resource Management in (2006), about half of the employees surveyed rated supervisor's respect for their ideas as "very important" to job satisfaction.

\section{$>$ Other Factors}

Although the aforementioned factors are considered important to achieve job satisfaction, several other factors contribute to achieving job satisfaction as well. Some factors are related to personal life and others are related to appreciation and praise. The Institute did not neglect these factors but focused on them as well, starting with providing fully furnished houses for faculty members, annual ceremonies, commercial discount programs, sports, and health activities, Stand with the employees in their joys and sorrows (Achievement report, 2019). All of these factors help increase employee loyalty and job satisfaction.

\section{CONCLUSION}

Job satisfaction is one of the most complex areas facing organizations today. It is related to many factors, including environmental, psychological, financial, and educational elements. It is difficult to limit them to just one or two factors. Additionally, many studies have shown how important these factors are and how their presence creates a healthy work environment and helps the employee to engage. The Institute of Public Administration is considered a successful example of how the senior management can seek to achieve job satisfaction for all employees by paying attention to the educational aspects of the employees as well as the social and psychological aspects. Eventually, all of these factors benefit the organization in achieving its goals and ambitions.

\section{REFERENCES}

[1] Achievement report. (2019). https://www.ipa.edu.sa/ar-sa/about/Pages/achievements.aspx

[2] Armstrong, M. (2006). A Handbook of Human resource Management Practice, Tenth Edition, Kogan Page Publishing

[3] Bacon, T. R. (2006). What people want: A manager's guide to building relationships that work. DaviesBlack Publishing.

[4] Best workplaces - Saudi Arabia - Great place to work. (2019, April 21). Great Place to Work. https:// www.greatplacetowork.me/best-work-places-saudi-arabia/ 
[5] Employee Job Satisfaction and Engagement Report. (2016). Society for Human Resource Management.

[6] Hashim, H., Saleh, A., Hashim, S., Kamarulzaman, N., \& Abdul-Ghani, A. (2011). An overview of the influence of physical office environments towards employee.

[7] Hoppock, R. (1935). Job Satisfaction, Harper and Brothers

[8] Locke, E. A. (1976). The nature and causes of job satisfaction. In M. D. Dunnette (Ed.), Handbook of industrial and organizational psychology

[9] Ministry of Human Resources and Social Development. (2020). Satisfaction Report | Arabic. https://hrsd.gov.sa/ar/node/770705

[10] Moyes, G. D., \& Shao, L. P., Newsome, M. (2008). Comparative analysis of employee job satisfaction in the accounting profession. Journal of Business \& Economics Research

[11] Rewards and Recognition: What's Really Driving Employee Engagement and Career Advancement. (2016). BambooHR

[12] Spector, P. E. (1997). Job satisfaction: Application, assessment, causes, and consequences. SAGE Publications.

[13] Statt, D. (2004). The Routledge Dictionary of Business Management, Third edition, Routledge Publishing

Citation: Fahad alrefaei. "Job Satisfaction: Analysis of the Institute of Public Administration" International Journal of Managerial Studies and Research (IJMSR), vol 8, no. 12, 2020, pp. 80-83. doi: https://doi.org/10.20431/2349-0349.0812008.

Copyright: () 2020 Authors. This is an open-access article distributed under the terms of the Creative Commons Attribution License, which permits unrestricted use, distribution, and reproduction in any medium, provided the original author and source are credited. 